as other drugs potentially toxic to the bone marrow were being taken.

\section{JONATHAN COOKE}

Pharmacy Department,

Leeds LS1 3EX

Seacroft Hospital,
Leeds LS14 $6 \mathrm{UH}$

' Winston DJ, Lau WK, Gale PG, Lowell SY. Trimethoprim-sulphamethoxazole for the treat-
ment of pneumonocystis carinii pneumonia. Ann ment of pneumonocystis

McKenna F, Davison AM, Giles GR. Response of pneumocystis carinii pneumonia only after highdose Co-trimoxazole. Lancet 1982;i:174.

\section{Failure patterns after total hip arthroplasty}

SIR,-Although we share Dr J E Charlton's enthusiasm for local anaesthesia during major hip surgery (5 February, $p$ 476) and also advocate the use of intrathecal narcotics for postoperative pain relief, ${ }^{1}$ we consider that the note of caution sounded by Dr D P Cartwright (26 February, p 721) is justified. Apart from the study by McLaren et $a l^{2}$ no other workers have been able to show such unfavourable results when general anaesthesia is compared with spinal anaesthesia. Indeed, Wickström et $a l^{3}$ were unable to find any difference in mortality after surgery for hip fracture in women geriatric patients when five anaesthetic methods were compared.

We should recognise that elderly patients with hip fractures do not constitute a population that can be compared with patients having total hip replacement for osteoarthrosis. Reduction in the incidence and extent of deep vein thrombosis may not automatically reduce the frequency of fatal pulmonary embolism. In the past year of about 300 patients having hip arthroplasty in our service five have died in the first three postoperative months. Three of these patients had spinal and two general anaesthesia. Although there may be somc selection of poorer risk patients for spinal anaesthesia, these are still in the minority and the figures do not support moves toward a radical change in anaesthetic practice as suggested in the last paragraph of Dr Charlton's letter.

J P AleXANDER D W BARRON

Division of Clinical Anaesthesia Withers Orthopaedic Centre, Musgrave Park Hospital, Belfast 9

' Barron DW, Strong JE. Post-operative analgesia in major orthopaedic surgery. Epidural and intrathecal opiates. Anaesthesia 1981;36:937-4

McLaren AD, Stockwell MC, Reid VT. Anaestheti techniques for surgical correction of fractured neck of femur. A comparative study of spinal and genera anaesthesia in the elderly. Anaesthesia 1978;33:10-4. Wickstrom 1, Holmberg 1, Stefansson T. Survival of female geriatric patients after hip racture surgery. Anaesthesiol Scand 1982;26:607-14.

\section{Is serum $\gamma$-glutamyltransferase a} misleading test?

SIR,-The recent review of serum $\gamma$-glutamyltransferase (12 February, $p$ 531) is to be applauded but for one notable omission which would add to $\mathrm{Mr} \mathrm{R}$ Penn's and Dr D Worthington's conclusion that measurement of this enzyme is of limited diagnostic value. I refer to the observation that serum $\gamma$ glutamyltransferase activity is raised in some patients with active rheumatoid arthritis. Reports on the incidence and cause of raised serum $\gamma$-glutamyltransferase activity in rheumatoid arthritis are conflicting, but they are agreed in so far as concentrations can be raised independently of drug treatment.

$\mathrm{Mr}$ Penn and Dr Worthington referred to the problems of defining normal serum ranges for $\gamma$-glutamyltransferase, and this has probably contributed to the discrepancies in results relating to rheumatoid arthritis. Lowe et $a l^{1}$ used 6-28 units/l for men and 4-18 units/1 for women and showed raised serum $\gamma$ glutamyltransferase activity in $77^{\circ}$, of patients. A later report ${ }^{2}$ using the same normal range limits indicated that $62 \%$ of patients with seropositive rheumatoid arthritis had raised serum $\gamma$-glutamyltransferase values compared with $43 \%$ with seronegative rheumatoid arthritis and $38 \%$ with ankylosing spondylitis. Spooner et al, ${ }^{3}$ however, used 1-35 units/1 as their normal range for both sexes and found that $23 \%$ of their patients with rheumatoid arthritis had raised serum $\gamma$-glutamyltransferase values.

In addition, the patients reported by Spooner et al may have had less active disease (mean erythrocyte sedimentation rate $32 \mathrm{~mm}$ in the first hour) than those reported by Lowe et al (mean erythrocyte sedimentation rate $47 \mathrm{~mm}$ in the first hour). This may also contribute to the different figures since there may be some correlation between serum $\gamma$-glutamyltransferase values and disease activity. ${ }^{1}$ Furthermore, liver involvement in some patients with rheumatoid arthritis is well recognised, but raised serum $\gamma$-glutamyltransferase is not necessarily a reflection of this.

Serum $\gamma$-glutamyltransferase values are undoubtedly raised in some patients with active rheumatoid arthritis but the origin and significance of this remains unclear.

J S Dixon

Clinical Pharmacology Unit,

(Rheumatism Research),

Royal Bath Hospital

Lowe JR, Pickup ME, Dixon JS, et al. Gamma glutamyl transpeptidase levels in arthritis: correlation with clinical and laboratory indices of disease activity. Ann Rheum Dis 1978;37:428-31.

Dixon JS, Bird HA, Wright V A comparison of serum biochemistry in ankylosing spondylitis, seronegative, and seropositive rheumatoid arthritis. Ann Rheum Dis 1981;40:404-8.

Spooner RJ, Smith DH, Bedford D, Beck PR. Serum gamma-glutamyltransferase and alkalin phosphatase in rheumatoid arthritis. I Clin Path

\section{Sun beds}

SiR,-Dr J L M Hawk (29 January, p 329) mentioned that skin cancers may develop in mice after continuous exposure to high doses of ultraviolet $\mathrm{A}$. This statement was based on a study by Urbach et al $^{1}$ showing that ultraviolet $A$ and ultraviolet $B$ induced tumours more rapidly than ultraviolet $\mathrm{B}$ alone. But the authors later attributed this tumour enhancing effect of ultraviolet $\mathrm{A}$ to differences in dose delivery rather than to differences in the ultraviolet spectrum." Until recently it has been assumed that ultraviolet $\mathrm{A}$ given intermittently in doses equivalent to those occurring in nature is not carcinogenic, ${ }^{2}$ and one study has shown that small doses of ultraviolet $\mathrm{A}$ might inhibit ultraviolet $\mathrm{B}$ induced skin tumours in mice. Based on these findings it has been stated that the use of potent artificial radiant sources of ultraviolet A for cosmetic purposes does not carry any risk for the human skin. ${ }^{4}$

We have studied the carcinogenic effect on hairless mice of ultraviolet $A$ irradiation in doses used in human solariums. ${ }^{5}$ Nine months of ultraviolet A irradiation alone induced no tumours. The combination of artificial ultraviolet sunlight (ultraviolet $\mathrm{A}$ and ultraviolet $\mathrm{B}$ ) and subsequent ultraviolet $A$ irradiation for 2-6 months, however, increased the tumour incidence about threefold as compared with artificial ultraviolet sunlight alone. This tumour enhancing effect of the radiation from the ultraviolet tubes with emission spectra similar to those used in human ultraviolet A solariums might, however, be partly or totally due to the small ultraviolet B component (below 320 $\mathrm{nm}$ ) emitted by the ultraviolet A bulbs. In a recent study, however, we have shown a tumour enhancing effect (at a reduced level) when the ultraviolet $A$ radiation was filtered through window glass to eliminate the radiation below $320 \mathrm{~nm}$.

People using ultraviolet A solariums for tanning purposes have probably been exposed previously to a great deal of natural sunlight and, therefore, it may be that ultraviolet $A$ irradiation in large "solarium like doses" is not as innocuous to the human skin as previously believed. ${ }^{4}$

Bent Staberg

Departments of Clinical Physiology

and Dermatology,

Finsen Institute

enhagen,

Urbach F, Epstein JH, Forbes PI. Ultraviolet carcinogenesis: experimental, global and genetic aspects. In: Pathak MA, Harber LC, Seiji M Kukita A, eds. Sunlight and man: normal and abnormal photobiologic respons
of 'Tokyo Press, 1974:259-83.

Parish JA, Anderson RR, Urbach F, Pitts D. $U V-A$ biological effects of ultraviolet radiation with emphasis on human responses to long-wave ultraviolet. New

Forbes PD, Davies RE, Urbach F. Experimental ultraviolet photocarcinogenesis: Wavelength interactions and time-dose relatic

von langwelligem Ultravioletlicht (UV-A) und von mittelwelliger Ultraviolettstrahlung (UV-B) auf die menschliche Haut. Ein kritischer Vergleich. $Z$. Hautkr 1980;55:497-513. taberg B, Wulf HC, Poulsen T, Klemp P, Brodthagen $\mathrm{H}$. The carcinogenic effect of sequential artificial sunlight + UVA irradiation. Consequences for solarium "therapy ?" Arch Dermatol (in

\section{Double indemnity in oesophageal carcinoma?}

SIR,-While the results of all forms of management of oesophageal carcinoma are depressing Mr R M Kirk (19 February, p 582) gives a gloomy representation of the role of resection. There could be no disagreement that an operative mortality of $30^{\prime \prime}$, is far too high, but it must be appreciated that this figure emerges from a comprehensive review of the published work over the last 30 years, including some patients treated in the 1940 s. $^{1}$ In attempting to relate operative mortality of resection to alternative forms of management results currently obtained in Britain must be considered.

The last two decades have seen importan advances in preoperative nutritional support, in operative techniques to minimise anastomotic leakage, and in postoperative management of such patients in intensive therapy units, with early elective ventilatory support, epidural analgesia, and thromboembolism prophylaxis. The application of these factors, accompanied by appropriate selection of those patients most likely to withstand and benefit from resection by virtue 
of age, intercurrent disease, and tumour staging, results in a hospital mortality nearer $10 \%$ as shown in several recent British studies. ${ }^{2-4}$ Indeed, in the latter quarter of the Lancaster series mortality has been reduced to $7 \%$ with no significant variation according to cell type. ${ }^{5}$

In considering alternatives to resection as suggested by Dr K F R Schiller (12 March, p 897) these too should be seen in true perspective. Fibreoptic endoscopic intubation has a hospital mortality of between $11 \%{ }^{6}$ and $27 \%{ }^{7}$ When used alone it denies the possibility of cure and cannot approach the $90 \%$ restoration of normal swallowing achieved by resection. ${ }^{4}$ Published results of radiotherapy are generally poor, with a $9 \%$ mortality for patients undergoing radical radiotherapy in one series ${ }^{8}$ and an overall five year survival rate of $4 \% .^{9}$ While many surgical series quote five year survival rates of $10-20 \%$ only one radiotherapeutic series claims to equal these albeit disappointing results. ${ }^{10}$

Clearly, prospective controlled trials are needed to establish the relative superiority of the various treatments as currently applied to favourable cases either alone or in combination, and fortunately these are now being established. In the current state of knowledge, however, resection in centres with an operative mortality comparable with that of palliative intubation should perhaps be considered as best fulfilling the objectives of management of this distressing disease-namely, the restoration of swallowing, prolonged useful survival, and an acceptable mortality for the chosen treatment.

A Warson

Royal Lancaster Infirmary,

Lancaster LA1 4RP

Earlam R, Cunha-Melo JR. Oesophageal squamous cell carcinoma 1 . A critical review of surgery. $\mathrm{Br} \mathcal{J}$ Surg 1980;67:381-90.

McKeown KC. Total three stage oesophagectomy for cancer of the oesophagus. Br $\mathcal{F}$ Surg 1976;63:25962.

Dark JF, Mousalli H, Vaughan R. Surgical treatment of carcinoma of the oesophagus. Thorax 1981; $36: 891-5$.

Watson A. A study of the quality and duration of survival following resection, endoscopic intubation and surgical intubation in
$B r \mathcal{F}$ Surg $1982 ; 69: 585-8$.

Watson A. Management of carcinoma of the oesophagus. In: Misiewicz JJ, Pounder RE, Venebles $\mathrm{CW}$, eds. Diseases of the gut and pancreas. London: Grant McIntyre Ltd (in press)

Ogilvie AL, Dronfield MW, Ferguson R, Atkinson $M$. Palliative intubation of oesophagogastric neoplasms at fibreoptic endoscopy. Gut 1982; 23:1060-7.

Jones DB, Davies PS, Smith PM. Endoscopic insertion of palliative endoscopic tubes in oesophagogastric neoplasms. Br F Surg 1981;68:197-8
Cedergvist C, Nielsen J, Berthelsen A, Hansen HS Cancer of the oesophagus II. Therapy and outcome. Acta Chir Scand 1978;144:223-40.

Earlam R, Cunha-Melo JR. Oesophageal squamous cell carcinoma II. A critical review of radiotherapy. Br F Surg 1979;66:110-2.

"Pearson JG. The present state and future potential

of radiotherapy in the management of esophagea

\section{Screening for fetal malformations}

SIR,-The paper from the University of Lund (5 March, $\mathrm{p}$ 747) left us with a sense of disappointment that in Sweden, as elsewhere, paediatricians and paediatric surgeons are not consulted about treatment of the malformed fetus. In some cases prenatal diagnosis can be a prelude to planned curative surgery rather than abortion.

One of the patients described by the authors had a fetus with exomphalos. If a chromosome disorder had been ruled out while doing the paracentesis, and the pregnancy had been allowed to go to full term, neonatal surgery would have been expected to produce an individual who was "normal" apart from a scar on the abdomen and unlikely to have long term complications. There is, of course, a recognised mortality with this type of surgery, particularly if the infant is born by premature labour or has other associated abnormalities, but the prognosis is by no means gloomy.

Must diagnostic studies on the fetus be only for the purpose of destroying any one that is not obviously normal?

R C M Cook IRENE $M$ IRVING

R E CUDMORE

Alder Hey Children's Hospital,

Liverpool L12 2AP

\section{Effect of genetic counselling on the} prevalence of Huntington's chorea

SIR,-We enjoyed reading the paper by Professor C O Carter and others (22 January, p 281) and would like to make the following points.

Firstly, it is not possible, on both theoretical and practical grounds, to identify and counsel all carriers before they begin their families. Many patients with Huntington's chorea show signs of the disease only in old age, by which time their children have married and produced children. Some carriers may even die before showing signs of the disease. Furthermore, there is a general reluctance, and rightly so, for doctors to diagnose Huntington's chorea when there is no family history available. Shaw and Caro ${ }^{1}$ have summarised the problems in eliciting an adequate family history. For these and many other reasons it is likely that a sizeable proportion of carriers in the population will not be identified and counselled in time before they produce children of their own.

Following the same lines of reasoning as in the paper we can show that the total number of carriers $\left(t_{n}\right)$, as a multiple of the mutation rate $m$, in the population in the nth generation is given by:

$t_{n}=(1-f)\left(t_{n-1}-2 m\right) s+f\left(t_{n-1}-2 m\right) c+2 m(s+1)$

where $f$ is the fraction of all carriers counselled, $\mathrm{s}$ is the reproductive fitness without counselling, $\mathrm{c}$ is the reproductive fitness with counselling, $t_{n-1}$ is the total number of carriers in the $(n-1)$ th generation. The value of $t_{0}$ is taken as $20 \mathrm{~m}$ (as in the paper). With the aid of a computer $t_{n}$ for a given nth generation can be calculated iteratively, beginning from $t_{0}$, and $t \infty$ can be readily estimated as the $t_{n}$ approaches the asymptotic value.

The table shows the values of $t 1, t 5, t 10$, and $t \infty$ for various values of $f$ and $s$. The value of $c$ is taken to be 0.5 , and one in 10 patients are considered to be new mutants (as in the paper). As the value of $f$ decreases $t \infty$ increases. If only $10 \%$ of carriers in the population are counselled the decrease in the prevalence is only about $25 \%(\mathrm{t} \infty=14 \cdot 9 \mathrm{~m})$.

If the value of $s$ is 1 (which is possible, as indicated in the paper) and if only $10 \%$ of all carriers are counselled the prevalence at equilibrium will be $42 \mathrm{~m}$, a twofold increase from the initial prevalence of $20 \mathrm{~m}$. In this case we can show (by putting $t_{1}-t_{0}=0$ and solving for $f$ ) that at least two out of nine $(22 \%)$ of all the carriers must be

Prevalence of carriers for various values of $f$ and $s$

\begin{tabular}{clrrrr} 
& & \multicolumn{4}{c}{ Prevalence of carriers at generation: } \\
\cline { 3 - 6 } $\mathrm{s}$ & $\mathrm{f}$ & \multicolumn{1}{c}{$\mathrm{t}_{1}$} & \multicolumn{1}{c}{$\mathrm{t}_{\mathrm{b}}$} & \multicolumn{1}{c}{$\mathrm{t}_{10}$} & \multicolumn{1}{c}{$\mathrm{t}$} \\
\hline 0.9 & 1.0 & $12.8 \mathrm{~m}$ & $6.1 \mathrm{~m}$ & $5.6 \mathrm{~m}$ & $5.6 \mathrm{~m}$ \\
& 0.5 & $16.4 \mathrm{~m}$ & $10.0 \mathrm{~m}$ & $8.3 \mathrm{~m}$ & $8.0 \mathrm{~m}$ \\
& 0.25 & $18.2 \mathrm{~m}$ & $13.9 \mathrm{~m}$ & $12.0 \mathrm{~m}$ & $11.0 \mathrm{~m}$ \\
& 0.1 & $19.3 \mathrm{~m}$ & $17.3 \mathrm{~m}$ & $16.0 \mathrm{~m}$ & $14.9 \mathrm{~m}$ \\
1.0 & 1.0 & $13.0 \mathrm{~m}$ & $6.4 \mathrm{~m}$ & $6.0 \mathrm{~m}$ & $6.0 \mathrm{~m}$ \\
& 0.5 & $17.5 \mathrm{~m}$ & $12.4 \mathrm{~m}$ & $10.6 \mathrm{~m}$ & $10.0 \mathrm{~m}$ \\
& 0.25 & $19.8 \mathrm{~m}$ & $19.0 \mathrm{~m}$ & $18.5 \mathrm{~m}$ & $18.0 \mathrm{~m}$ \\
& 0.1 & $21.1 \mathrm{~m}$ & $25.0 \mathrm{~m}$ & $28.8 \mathrm{~m}$ & $42.0 \mathrm{~m}$ \\
1.1 & 1.0 & $13.2 \mathrm{~m}$ & $6.8 \mathrm{~m}$ & $6.4 \mathrm{~m}$ & $6.4 \mathrm{~m}$ \\
& 0.5 & $18.6 \mathrm{~m}$ & $15.3 \mathrm{~m}$ & $13.8 \mathrm{~m}$ & $13.0 \mathrm{~m}$ \\
& 0.25 & $21.3 \mathrm{~m}$ & $25.9 \mathrm{~m}$ & $30.4 \mathrm{~m}$ & $46.0 \mathrm{~m}$ \\
& 0.1 & $22.9 \mathrm{~m}$ & $35.8 \mathrm{~m}$ & $55.1 \mathrm{~m}$ & $\mathrm{t} 1000=$ \\
& & & & & $8 \times 10^{18} \mathrm{~m}$
\end{tabular}

$\mathrm{f}=$ Fraction of all carriers counselled.
$\mathrm{s}=$ Reproductive fitness of carriers without counselling. counselled to prevent a further rise in the prevalence of the disease. If the value of $s$ is greater than 1 say $1 \cdot 1$ ) then an even greater proportion of carriers must be counselled (in this case $37 \%$ ) if there is to be no further rise in the prevalence.

Thus while genetic counselling of the children of patients with Huntington's chorea can be effective in preventing the birth of more carriers in the family concerned a substantial reduction in the prevalence of the disease in the population may be doubtful in some circumstances, depending on the fraction of all the carriers counselled and the reproductive fitness of the carriers without counselling.

JoHN S H TAY WILLIAM C L YiP

University Department of

Paediatrics,

Singapore General Hospital,

' Shaw M, Caro A. The mutation rate to Huntington's chorea. $\mathcal{F}$ Med Genet 1982;19:161-7.

***We sent a copy of this letter to the authors,

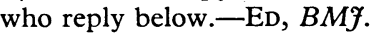

SIR,-With a mean age of onset at about 40 years most children of patients may be counselled in time provided that the diagnosis is made promptly. Table $I$ in our article showed that in our series 82 were counselled before and 30 after they had started their families. A medical profession alerted to making a diagnosis could improve on this.

C O CARTER

Keston Park,

M BARAITSER

Hospital for Sick Children,

\section{Missed jaundice in black infants}

SIR,-The two patients first described in the lesson of the week on missed jaundice in black infants ( 5 February, p 463) seem to be negroid; one very darkly pigmented ("a black boy") and one less so ("a brown skinned girl"). Dr Malcolm A Lewis subsequently writes referring to them as "coloured infants" and adds two cases of his own whom he describes as "an Asian girl" and "a boy of Ugandan Asian parents." The lesson of the week goes on to exhort us to suspect jaundice in "non-white infants."

The above descriptions of racial pigmentation are clearly a mess and unsuited to a scientific medical journal, although they have become commonplace in newspapers and on politicians' lips. Black and white have no meaning in genetic terms and certainly not when discussing racial glucose 6 phosphate dehydrogenase deficiency. The classification of races into caucasoid, congoid (negroid), mongoloid, australoid, and capoid with a description of the degree of pigmentation of skin where necessary is followed in many publications and, although perhaps a nuisance, is clearly very much more accurate and appropriate to medicine.

I was given a book to review recently entitled Atlas of Black Dermatology. It turned out to be mainly about the American negro, and the excellent photographs showed that he was every colour but certainly not black. Black dermatology sounds a disreputable art in any case. 